\title{
Impact of plate Osteosynthesis on functional outcome in displaced midshaft Clavicular Fractures: a prospective observational study
}

\author{
Gohiya $\mathrm{A}^{1}$, Singh $\mathrm{BS}^{2}$, Sharma $\mathbf{P}^{3}$, Gaur $\mathrm{S}^{4}$ \\ ${ }^{1}$ Dr Ashish Kumar Gohiya, Associate Professor, ${ }^{2}$ Dr Sushan Singh Bhasin, Resident, ${ }^{3}$ Dr Pulak Sharma, Assistant Professor, \\ ${ }^{4}$ Dr Sanjiv Gaur, Professor and Head. All are affiliated with Dept of Orthopedics Gandhi Medical College Bhopal
}

Address for correspondence: Dr Ashish Gohiya, Email: gohiyapoorva@gmail.com

\begin{abstract}
Introduction: Fractures of the clavicle are common, accounting for $2.6-4 \%$ of adult fractures and $35 \%$ of injuries to the shoulder girdle. Fractures of the shaft account for $69-82 \%$ of all fractures. Prevalence of non-union or mal-union in displaced midshaft clavicular fractures after conservative treatment is higher than previously presumed. Plate fixation can help obtain firm anatomical reduction in severe displaced or comminuted fracture. We have taken up this study to evaluate the functional outcome after plate osteosynthesis ofclavicular fractures. Materials and Methods: This is a prospective study done in Department of Orthopedics at tertiary care teaching hospital in central India over period of 1 year. The patients who presented with fracture clavicle and fulfilled the inclusion criteria were studied. Functional outcome was evaluated using modified Constant and Murley scoring system. Results: 24 patients of displaced midshaft clavicle fracture matching inclusion criteria were included in this study. Follow up evaluation of the patients was done at the desired interval with a minimal follow up of 6 months. $52.17 \%$ were in the age group of $20-29$ years. $73.91 \%$ of patients studied were males. Type- 2 middle third fracture type-2 B1 was encountered in 78.26 \% of patients. The mean modified Constant Shoulder Score was 65.39 with range 48-72. In this study 17 patients $(73.91 \%$ ) had very good functional outcome. Conclusion: Use of locking plates for displaced midshaft clavicle fractures results in early union with very good functional outcome and is associated with very low complication rates.
\end{abstract}

Key words: Mid Shaft Clavicular Fracture, Osteosynthesis, Functional Outcome.

\section{Introduction}

Fractures of the clavicle are common, accounting for 2.6$4 \%$ of adult fractures and $35 \%$ of injuries to the shoulder girdle. They occur most commonly in young individuals especially males (68\%). Fractures of the shaft account for $69-82 \%$ of all fractures, lateral-end injuries account for 21-28\%, and medial-end injuries account for 2-3\% [1]. The incidence of nonunion in displaced comminuted midshaft clavicle fractures in adults is between 10 and $15 \%$ [3]. The prevalence of non-union or mal-union in displaced midshaft clavicular fractures after conservative treatment is higher than previously presumed. A reduced rate of nonunion after primary treatment with plate fixation (2.2\%) compared with non-operative care $(15.1 \%)$ has been found. A clear superiority of operative fixation has been documented against conservative management in various studies [4]. Patients who were operated had better outcome, earlier return to normal function and against the popular opinion, they were more

Manuscript received: $4^{\text {th }}$ Jan 2015

Reviewed: $19^{\text {th }}$ Jan 2015

Author Corrected: $5^{\text {th }}$ Feb 2015

Accepted for Publication: $15^{\text {th }}$ Feb 2015 satisfied with the cosmetic appearance than their conservatively managed counterparts [5]. There are various methods for treating clavicle mid shaft fractures, such as intramedullary K-wires or Steinmann pins fixation and plate fixation. In particular, plate fixation can help obtain firm anatomical reduction in severe displaced or comminuted fracture. There are various plates including reconstruction plates, locking reconstruction plates, dynamic compression plates and semitubular plates. Among them, anatomical locking compression plate and locking reconstruction plate, which can be bent to the Sshaped curvature of the clavicle, are the most preferred. We have taken up this study to evaluate the functional outcome after plate osteosynthesis of clavicular fractures

Aims

The aim of this study is to evaluate the impact of plate osteosynthesis on functional outcome in displaced midshaft clavicular fractures and also its impact on duration of union.

\section{Materials and Methods}

Available online at: www.ijmrr.in 366 | P a g e 
This prospective study was conducted at Department of Orthopaedics at Gandhi Medical College and Hamidia Hospital, Bhopal over a period of 1 year. All patients presenting with clavicle fractures were included in this study as per inclusion/ exclusion criteria and their details were noted in the proforma.

\section{Inclusion Criteria}

1. Age $\geq 18$ years and $\leq 60$ years

2. Closed fractures of midshaft clavicle

3. Comminuted and displaced fractures of clavicle

4. Time since injury less than 3 weeks

\section{Exclusion Criteria}

1. Age $<18$ years and $>60$ years

2. Open fractures

3. Fracture in lateral and medial third of clavicle

4. Time since injury more than 3 weeks

\section{Research Article}

5. Pathological fractures

6. Undisplaced fractures

7. Associated head injury.

Detailed examination was done of the injury site was recorded in the proforma. Routine investigations were done preoperatively.

Regular follow up for every 4 weeks was done. Local examination of the affected clavicle for tenderness, instability deformity and shoulder movements were assessed. X-rays were taken at each follow up visits to known about progress of fracture union and implant position. Rehabilitation of the affected extremity was done. Patients were followed up till radiological union. Modified Constant and Murley score [2] was used to assess the functional outcome. Final follow up was done at the end of 6 months.

\section{Evaluation of Functional Outcome}

Functional outcome evaluation was done using modified Constant and Murley scoring [2] which has subjective and objective parameters. Patients were not assessed on the basis of power of abduction. Final grading of functional outcome was done as mentioned below.

\begin{tabular}{|l|l|}
\hline Total score & Result \\
\hline $64-75$ & Very good \\
\hline $52-63$ & Good \\
\hline $40-51$ & Mean \\
\hline$<40$ & Poor \\
\hline
\end{tabular}

\section{Results}

Twenty-four patients of displaced mid shaft clavicle fracture matching inclusion criteria were included in the study. All the patients were evaluated and operated as per the standard protocol. Follow up evaluation of the patients was done at the desired interval as per Performa with a minimal follow up of 6 months. One patient was lost to follow-up, so final analysis consists of 23 patients.

Age and Sex Incidence: $52.17 \%$ of patients belong to age group 20-29 years.73.91\% of patients studied were males.

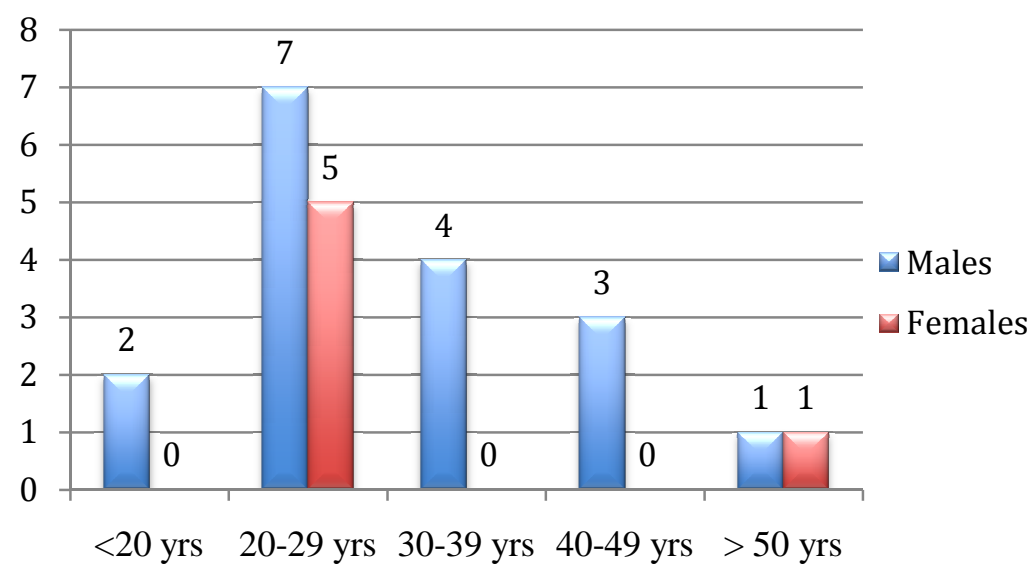


Classification: Fracture was classified as per Robinson Classification.[6]

Table -I: Fracture was classified as per Robinson Classification

\begin{tabular}{|l|l|}
\hline Robinson Classification Type & Number of patients \\
\hline 2B1 & 18 \\
\hline 2B2 & 5 \\
\hline
\end{tabular}

Type-2 middle third fracture type-2 B1 (displaced with simple or single butterfly fragment) was encountered in 18 patients $(78.26 \%)$ while 5 patients $(21.74 \%)$ had type-2 B2 (displaced with comminuted or segmental).

Table- II: injury to surgery interval

\begin{tabular}{|l|l|l|}
\hline Duration of stay & Number of patients & Percentage \\
\hline$<1$ Week & 18 & $78.26 \%$ \\
\hline $1-2$ Weeks & 3 & $13.04 \%$ \\
\hline$>2$ Weeks & 2 & $8.70 \%$ \\
\hline TOTAL & $\mathbf{2 3}$ & $\mathbf{1 0 0}$ \\
\hline
\end{tabular}

In this study, 18 patients $(78.26 \%)$ were operated within 2 weeks and 5 patients $(21.74 \%)$ were operated between 2 to 4 weeks.

Duration of Hospital Stay: Average duration of stay in the hospital was 7.52 days (Range 3-26 days). (Table II)

Table- III: Type of plate used

\begin{tabular}{|l|l|l|}
\hline Type of plate used & Number of patients & Percentage \\
\hline Locking reconstruction plate & 19 & $82.61 \%$ \\
\hline Anatomical locking compression plate & 4 & $17.39 \%$ \\
\hline Total & $\mathbf{2 3}$ & $\mathbf{1 0 0}$ \\
\hline
\end{tabular}

19 patients $(82.61 \%)$ were operated using locking reconstruction plates while in another 4 patients (17.39\%) anatomical locking compression plates were used. (Table III)

Table- IV: Functional Outcome:

\begin{tabular}{|l|l|}
\hline Functional Outcome & Number of Patients \\
\hline Very Good & 17 \\
\hline Good & 5 \\
\hline Mean & 1 \\
\hline Poor & 0 \\
\hline
\end{tabular}

Table -V: Functional Outcome with Respect To Age

\begin{tabular}{|c|c|c|c|c|}
\hline & \multicolumn{4}{|c|}{ Number of Patients with functional outcome } \\
\hline Age Group & Very good & Good & Mean & Poor \\
\hline$<20$ years & 2 & 0 & 0 & \\
\hline $20-29$ years & 9 & 2 & 1 & \\
\hline $30-39$ years & 4 & 0 & 0 & \\
\hline $40-49$ years & 2 & 1 & & \\
\hline$>50$ years & & 2 & & \\
\hline
\end{tabular}

The functional outcome is assessed by modified Constant and Murley score. The mean modified Constant Shoulder Score was 65.39 with range $48-72$. We had 17 patients $(73.91 \%)$ with very good functional outcome, 5 patients $(21.74 \%)$ with good functional outcome. 
Table -VI: Functional Outcome with Respect to Injury to Surgery Interval

\begin{tabular}{|l|l|l|l|l|}
\hline \multirow{2}{*}{ Time Interval } & \multicolumn{4}{|l|}{ Number of Patients with functional outcome } \\
\cline { 2 - 5 } & Very good & Good & Mean & Poor \\
\hline$<2$ weeks & 13 & 5 & 0 & 0 \\
\hline 2 to 4 weeks & 4 & 0 & 1 & 0 \\
\hline
\end{tabular}

Table -VII: Functional Outcome with Respect to Fracture Classification

\begin{tabular}{|l|l|l|l|l|}
\hline \multirow{2}{*}{ Classification } & \multicolumn{4}{|l|}{ Number of Patients with functional outcome } \\
\cline { 2 - 5 } & Very Good & Good & Mean & Poor \\
\hline 2B1 & 16 & 2 & 0 & 0 \\
\hline 2B2 & 1 & 3 & 1 & 0 \\
\hline
\end{tabular}

Table- VIII: Time take for Union

\begin{tabular}{|l|l|l|}
\hline Time of union & Number of patients & Percentage \\
\hline $6-8$ weeks & 2 & $8.70 \%$ \\
\hline $8-10$ weeks & 16 & $69.56 \%$ \\
\hline $10-12$ weeks & 5 & $21.74 \%$ \\
\hline$>12$ weeks & 0 & $0 \%$ \\
\hline Total & 23 & 100 \\
\hline
\end{tabular}

All patients had their fractures united by 12 weeks. No non-unions or malunions were seen. Average time to union was 8.68 weeks.

Figure- 1: Serial X-rays of patient

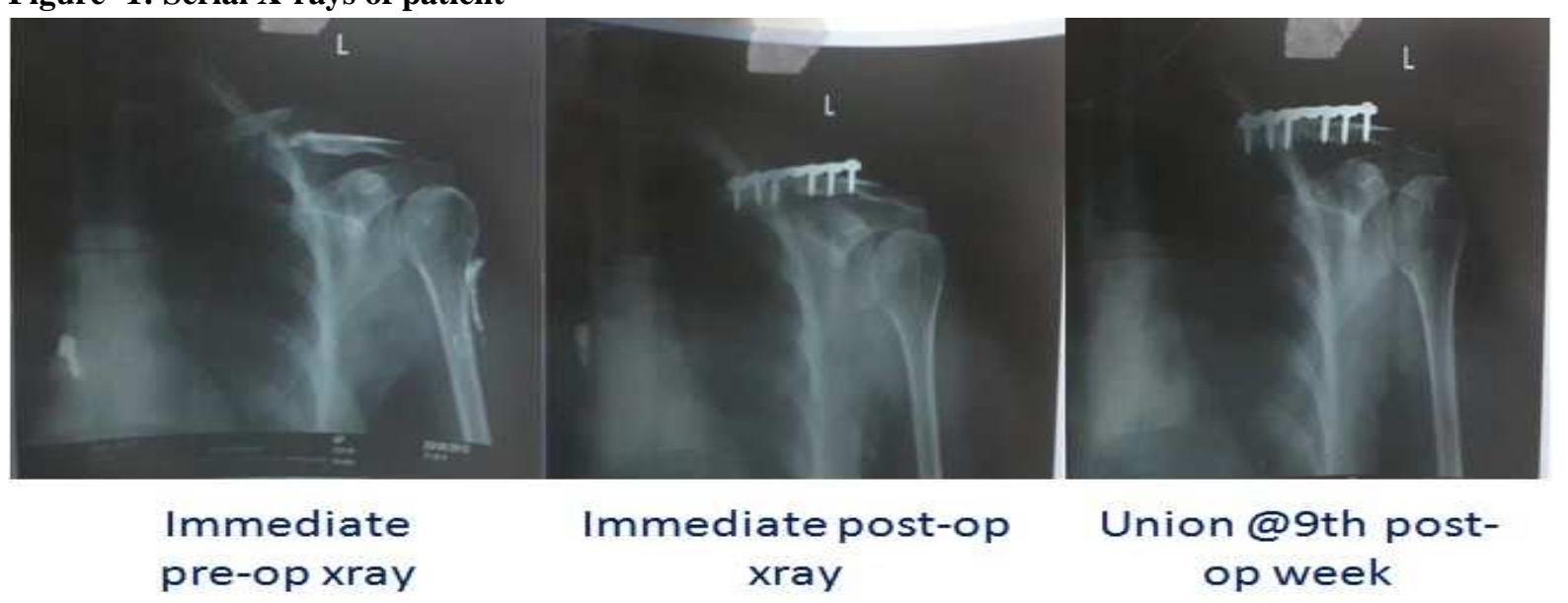

Complications: Major complication: A complication requiring inpatient treatment and resulting in an additional morbidity of 2 months or more was regarded as a major complication [7].

In our study one patient had plate loosening which required implant removal after union. One patient had plate prominence and another patient had superficial surgical site infection which required oral antibiotics. No major complications occurred in our study.

\section{Discussion}

Historically clavicle fractures have been treated conservatively. Other studies reported poor results following conservative treatment displaced middle third clavicle fracture $[4,8,9]$. In the study by ShenW $\mathbf{J}$ et al, 251 fresh completely displaced clavicle fractures were

International Journal of Medical Research and Review operated by means of Mizuho C-type plate or an AOASIF $3.5 \mathrm{~mm}$ reconstruction plates[10]. In the study by WgCdr V Kulshrestha twenty cases of displaced/comminuted midshaft clavicle fractures were fixed using reconstruction plates [11]. In our study $17(73.91 \%)$ patients with middle third clavicle fracture, had road traffic accident \& fall on outstretched hand in 5 patients $(21.74 \%)$. In the study done by Bostman et al, the Available online at: www.ijmrr.in 369 | P a g e 


\section{Research Article}

causes of injury were due to two wheeler accidents in $(36.8 \%)$, fall in $23.30 \%$, motor vehicle accident in $18.45 \%$ and sports in injury $21.36 \%$ patients [7]. In Cho et al study, in reconstruction plate group there were 13 patients who sustained road traffic accident [12]. The injury pattern in our study might be due to the fact that two wheelers are the most common mode of transportation in our region.

The age profile of our study was similar to other studies $[11,12,13]$. There was a male preponderance in our study which is similar to other studies

Out of the 23 patients, 18 were classified as type $2 \mathrm{~B} 1$ and 5 patients as type $2 \mathrm{~B} 2$. The study conducted by Modi et al had $52.8 \%$ of type $2 \mathrm{~B} 1$ fractures. Similar percentage of Type2B1 fractures was reported in studies done by Bostman and Cho et al [7,12].

Injury to surgery interval was 2 weeks in $78.26 \%$ of patients as they presented late. All the studies reported in western literature(Bostman and Cho et al) had injury to surgery interval of maximum 9 days, this difference may be because of better health seeking behavior of western population.

In our study $69.56 \%$ of the treated fractures united between 8-10 weeks with a mean duration of 8.68 weeks. We had no mal -unions or non- unions. In the study conducted by Shen $\mathrm{J}$ W et al 7\%of the patients develop non-union[10]. The mean time to union was 10 weeks. The study done by V Kulshreshta had also shown mean time to union as 8 weeks. In the study done by Cho et al longest time to reunion has been reported and that is 13.2 weeks $[11,12]$.

None of patients in the study had major complications. Two patients had minor complications out of them one had plate loosening and the other patient had superficial surgical site infection which was treated by oral antibiotics. Similar results with respect to minor and major complications have been observed in studies conducted by V Kulshreshta and Cho et al.[11,12]

The functional outcome according to modified Constant and Murley scoring system in this study showed very good results in 17 Patients $(73.91 \%)$ and good functional outcome in 5 patients $(21.74 \%)$. Mean functional outcome in 1 patient who had severe comminution at the fracture site along with delay of 19 days in fixation. In the study by Kulshrestha et al., comparing conservative and operative interventions for displaced midshaft clavicle fractures, Constant shoulder scores were significantly better for operative group $(\mathrm{P}<0.0001)$ [11]. In a study by
Douraiswami et al. the functional outcome was assessed using DASH scores and Simple Shoulder Test (SST). All patients were satisfied with the outcome. $84 \%$ of patients returned to their work by 6 weeks [14]. Thus the functional outcome of our study cohort was in concordance to other studies.

\section{Conclusion}

This prospective study thus concludes that use of locking plates for displaced midshaft clavicle fractures results in early union with very good functional outcome and is associated with very low complication rates. However small sample size is a limitation of our study.A multicenter randomized clinical study is recommended for proving the superiority of operative management over conservative.

Funding: Nil, Conflict of interest: None initiated.

Permission from IRB: Yes

\section{References}

1. Kashif Khan LA, Bradnock TJ, Scott C, Robinson CM. Fractures of the clavicle. J Bone Joint Surg Am. 2009; 91:447-460.

2. Constant CR, Murley AH. A Clinical method of functional assessment of the shoulder. ClinOrthopRelat Res. 1987 Jan;(214):160-4.

3. Schiffer G, Faymonville C, Skouras E, Andermahr J, JubelA: Midclavicular fracture: Not just a trivial injurycurrent treatment options. DtschArztebl Int. 2010 Oct; 107(41):711-7.

4. Zlowodzki M, Zelle BA, Cole PA, Jeray K, McKee MD. Evidence-based orthopaedic trauma working group. Treatment of acute midshaft clavicle fractures: systematic review of 2144 fractures: on behalf of the Evidence-Based Orthopaedic Trauma Working Group. J Orthop Trauma. 2005 Aug;19(7):504-7.

5. Altamimi SA, McKee MD; Canadian Orthopaedic Society. Non-operative treatment compared with plate fixation of displaced midshaft clavicle fractures. Surgical technique. J Bone Joint Surg Am. 2008 Mar;90 Suppl 2 Pt $1: 1-8$.

6. Robinson CM. Fractures of the clavicle in the adult. Epidemiology and classification. J Bone Joint Surg Br. 1998 May;80(3):476-84. 
7. Bostman O, Manninen M, Pihlajamaki $\mathrm{H}$ Complications of plate fixation in fresh displaced midclavicular fracture. J Trauma. 1997 Nov;43(5):778-83.

8. Hill JM, McGuire MH, Crosby LA. Closed treatment of displaced middle-third fractures of the clavicle gives poor results. J Bone Joint Surg Br. 1997 Jul;79(4):537-9.

9. Nordqvist A, Petersson C. The incidence of fractures of the clavicle. ClinOrthopRelat Res. 1994 Mar;(300):12732.

10. Shen WJ, Liu TJ, Shen YS. Plate fixation of fresh displaced midshaft clavicle fractures. Injury. 1999 Sep;30(7):497-500.

\section{Research Article}

11. Kulshrestha V. Primary plating of displaced mid-shaft clavicular fractures. Med J Armed Forces India. 2008; 64(3):208-211.

12. Chul-Hyun Cho, Kwang-Soon Song, Byung-Woo Min, Ki-CheorBae, Kyung-Jae Lee. Reconstruction Plate versus Reconstruction Locking Compression Plate for Clavicle Fractures. ClinOrthop Surg. 2010 Sep;2(3):154-9.

13. Modi N, Patel AD, P. Hallam, Outcome of 62 Clavicle Fracture Fixations with Locked Compression Plate: Is this the right way to go?Injury Extra 09/2011; 42(9):118-118.

14. Douraiswami B, Naidu D K, Thanigai S, Anand V, Dhanapal R. Open reduction and plating for displaced mid third clavicle fractures. A prospective study. J ClinOrthop Trauma. 2013 Dec; 4(4): 174-179.

\section{How to cite this article?}

Gohiya A, Singh BS, Sharma P, Gaur S. Impact of plate Osteosynthesis on functional outcome in displaced midshaft Clavicular Fractures: a prospective observational study. Int J Med Res Rev 2015;3(4):366-371. doi: 10.17511/ijmrr.2015.i4.069. 